\title{
The Open Allergy Journal
}

\author{
Content list available at: https://openallergyjournal.com
}

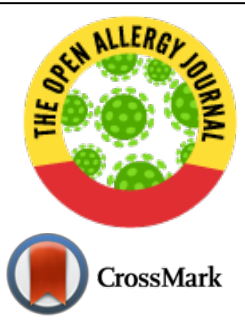

\section{RESEARCH ARTICLE}

\section{Association Between Endoscopic, Radiologic and Patient-reported Chronic Rhinosinusitis with Nasal Polyps}

A. Luukkainen ${ }^{1,2}$, J. Numminen ${ }^{3}$, M. Rautiainen ${ }^{3}$, A. Julkunen ${ }^{1}$, H. Huhtala ${ }^{4}$, J. Lampi ${ }^{5,6}$, A. Markkola ${ }^{7}$, J. Myller ${ }^{8}$, A.K. Andiappan $^{9}$, D.Y. Wang ${ }^{2}$ and S. Toppila-Salmi, ${ }^{1,10, *}$

${ }^{1}$ Haartman Institute, University of Helsinki, Helsinki, Finland

${ }^{2}$ Department of Otolaryngology, Yong Loo Lin School of Medicine, National University of Singapore 119228, Singapore

${ }^{3}$ Department of Otorhinolaryngology, Tampere University Hospital and Tampere University, Faculty of Medicine and Life Sciences, Tampere, Finland

${ }^{4}$ Faculty of Social Sciences, Tampere University, Tampere, Finland

${ }^{5}$ Living Environment and Health Unit, National Institute for Health and Welfare, Helsinki, Finland

${ }^{6}$ Environment Health Unit, National Institute for Health and Welfare, PO Box 95, FI-70701, Kuopio, Finland

${ }^{7}$ Department of Radiology, Helsinki University Central Hospital, Helsinki, Finland

${ }^{8}$ Department of Otorhinolaryngology, Päijät-Häme Central Hospital, Lahti, Finland

${ }^{9}$ Singapore Immunology Network (SIgN), Agency for Science, Technology and Research (A*STAR), Singapore, Singapore

${ }^{10}$ Skin and Allergy Hospital, University of Helsinki and Helsinki University Hospital, Helsinki, Finland

\begin{abstract}
:
Objectives:

Chronic Rhinosinusitis without Nasal Polyps (CRSsNP) and with Nasal Polyps (CRSwNP) affect 10\% and 1-4\% of the general population respectively. Early detection and treatment of CRSwNP might prevent recalcitrant disease forms. The aim of this prospective controlled study was to evaluate association between endoscopic, radiologic, and self-reported CRSwNP, and a family history in defining CRSwNP.

Methods:

This study involved 73 CRS patients aged 18 years or over undergoing CRS-surgical consultation at the Tampere University Hospital. Data of sinus Computed Tomography (CT) scans and nasal endoscopy was obtained from patient records. Sixty controls \pm allergic rhinitis underwent clinical examination. All subjects filled a questionnaire. Associations were analyzed by Chi square and adjusted regression models. The predictive performance of various parameters was assessed using the Area Under the Receiver Operating Characteristic curve (AUROC).

Results:

A total of $33 \%$ of CRSwNP patients reported not having Nasal Polyps (NPs), while $18 \%$ of CRSsNP patients reported having NPs ( $p<0.001$ ) Radiologic Nasal Polyp (NP) score differentiated CRSwNP from CRSsNP with an AUROC of 0.95 (95\% CI 0.91-1.00). The AUROC value for Lund-Mackay (LM) score was 0.84 (0.75-0.94). Positive family history of NP did not differ significantly between CRS and control groups. Family history of allergy or asthma was given with certainty, whereas CRS patients had uncertainty of reporting NPs in family compared to controls (adjusted OR=6.02, 95\% CI 1.98-18.30, $p=0.002$ ).

Conclusion:

Our findings suggest that in situations where nasal endoscopy cannot be performed, early detection of CRSwNP could result from information obtained from sinus CT scans and patients, in comparison to family history which has lower predictive value. However validation studies with larger sample sizes are still needed.
\end{abstract}

Keywords: Allergic rhinitis, Asthma, Nasal polyps, Rhinosinusitis, Nasal endoscopy, CT scan. 


\section{INTRODUCTION}

Chronic Rhinosinusitis (CRS) is an inflammatory disorder of the nose and paranasal sinuses lasting for at least 12 weeks and affects $10.9 \%$ of the European population [1,2]. While $1-4 \%$ of the general population report having Nasal Polyps (NP), the occurrence of CRSwNP has been shown to be more prevalent in patients reporting a positive family history of NP and in patients with respiratory phenotypes such as asthma and Allergic Rhinitis (AR) [3 - 6]. The prevalence of AR is $10-30 \%$ and asthma $1-18 \%$ in the general population their risk is strongly associated to a family history of asthma or allergy [7 - 9]. Thus, early awareness and treatment of CRSwNP might prevent recalcitrant disease forms and asthma $[10,11]$. The aim of this prospective controlled study was to evaluate association between endoscopic, radiologic, self-reported CRSwNP, and family history in detecting CRSwNP. The hypothesis was that radiologic, self-reported and heredity of NPs would all have high predictability of CRSwNP phenotype.

\section{MATERIALS AND METHODS}

\subsection{Subjects}

The study was approved by the ethical committees of the Pirkanmaa Hospital district (no R06187, R04044) and of Hospital District of Helsinki and Uusimaa (no 19/13/03/00/11) The research was conducted in accordance with the Helsinki Declaration and the National laws. Written informed consent was obtained from each patient. This prospective study was carried out at the Department of Otorhinolaryngology, Tampere University Hospital, Finland and the Skin and Allergy Hospital, Helsinki University Hospital from 2006 to 2012. A sample of 73 adult patients with CRS suspicion underwent sinus CT scans as previously described [12]. Subject characteristics are presented in Table 1. CRS was diagnosed according to the European Position Paper on CRS and nasal polyps (typical symptoms and nasal endoscopic signs) and a total Lund-Mackay score over 0/2 [1, 13]. Signs of NPs were evaluated by patient record information of nasal endoscopy performed during CRS-surgery or at outpatient clinic (for those who were not operated) at the time of CT scans and questionnaire. Exclusion criteria were allergic or non-allergic fungal sinusitis, antrochoanal polyps, cystic fibrosis, and primary ciliary dyskinesia.

The control group consisted of 60 adult volunteer subjects who were healthy $\pm A R$. Initial exclusion criteria in the recruitment of controls were smoking and any other disease besides AR. CRS was excluded by both interview and by nasal endoscopy by Otorhinolaryngologist (JN and ST-S). Deviation from protocol: NP was diagnosed by anterior rhinoscopy from $\mathrm{n}=20$ controls with a good visualization to middle meatal area. The baseline data of all subjects was obtained from medical records and by a questionnaire as previously described [14]. Despite exclusion criteria in the interview, $5 \%$ of controls reported in the questionnaire as having asthma in the questionnaire (Table 1).

\footnotetext{
* Address correspondence to this author at the Skin and Allergy Hospital, Helsinki University Hospital, PO BOX 160 (Meilahdentie 2), 00029 Hospital District of Helsinki and Uusimaa, Helsinki, Finland; Tel: +358-9-4711; Fax: +358-9-19125155, E-mail: sanna.salmi@helsinki.fi
}

\subsection{Questionnaires}

The following questions were asked in the questionnaire: Are you a current smoker? (no, yes). Have you ever smoked? (no, yes). Do you have atopy, AR, asthma, Aspirin Exacerbated Respiratory Disorder (AERD)? (no,yes). Do you have a family history of AR? (no, yes, I don't know). Do you have a family history of asthma? (no, yes, I don't know). Do you have a family history of nasal polyps? (no, yes, I don't know). Are you currently using nasal medication? (no, intranasal corticosteroid, intranasal corticosteroid + peroral antihistamine). Have you used peroral corticosteroid course(s) during the past 12 months? (no, yes, if yes how many).

The following information was obtained from questionnaire and/or patient medical records at Tampere University Hospital: gender, age, skin prick test results, radiologic and endoscopic signs of nasal polyps (no, yes) and of previous operations (no, yes), previous sinonasal operation (no, yes) and other diseases besides asthma, AR and CRS.

\subsection{CT-scans}

CT scans were routinely performed and evaluated by an ENT Radiologist (AM) from all 74 CRS patients as previously described [12]. In this study we used the data of the LundMackay score of sinus CT-scans; and sum of maxillary/ ethmoid sinus mucosal findings (scored as $0=$ no change, $1=$ mucosal thickening, 2 = polypous mucosal thickening \pm discharge) and detectability of turbinate structures (scored as $0=$ detected; $1=$ not detectable), yielding a total maximum radiologic NP score of 16 (Fig. 1, Table 2).

\subsection{Statistical Analysis}

Statistics were performed with SPSS 22.0 statistical software package (IBM SPSS Statistics for Windows, Armonk, NY: IBM Corp. Released 2013). Associations were assessed by the Fisher's exact test (dichotomous) and Kruskal-Wallis and Mann Whiteny U test (continuous). Heredity was studied in binary logistic regression models adjusted by the following potential confounding factors: age, gender, subject's AR and subject's asthma. Radiologic scores were entered into a Receiver Operating Characteristic (ROC) curve. The predictive performance of various parameters was assessed by using the Area Under The Receiver Operating Characteristic curve (AUROC). Two-tailed $P$-values of $<0.05$ were considered statistically significant.

\section{RESULTS}

The subject characteristics used in this study are presented in Table 1. The proportion of subjects reporting AR was significantly higher in the control group than in the CRS group $(p=0.03)$. The proportion of subjects reporting intranasal corticosteroid use, and having undergone previous sinonasal operations were significantly higher in the CRS group compared to the control group $(p<0.001, p=0.001$, respectively, Table 1). The median age of the CRS group was significantly higher compared to the control group $(p<0.001$, Table 1). When comparing to the CRS subgroups, the proportion of patient reporting asthma or AERD was significantly higher in the CRSwNP group compared to the CRSsNP group $(p<0.001$, 

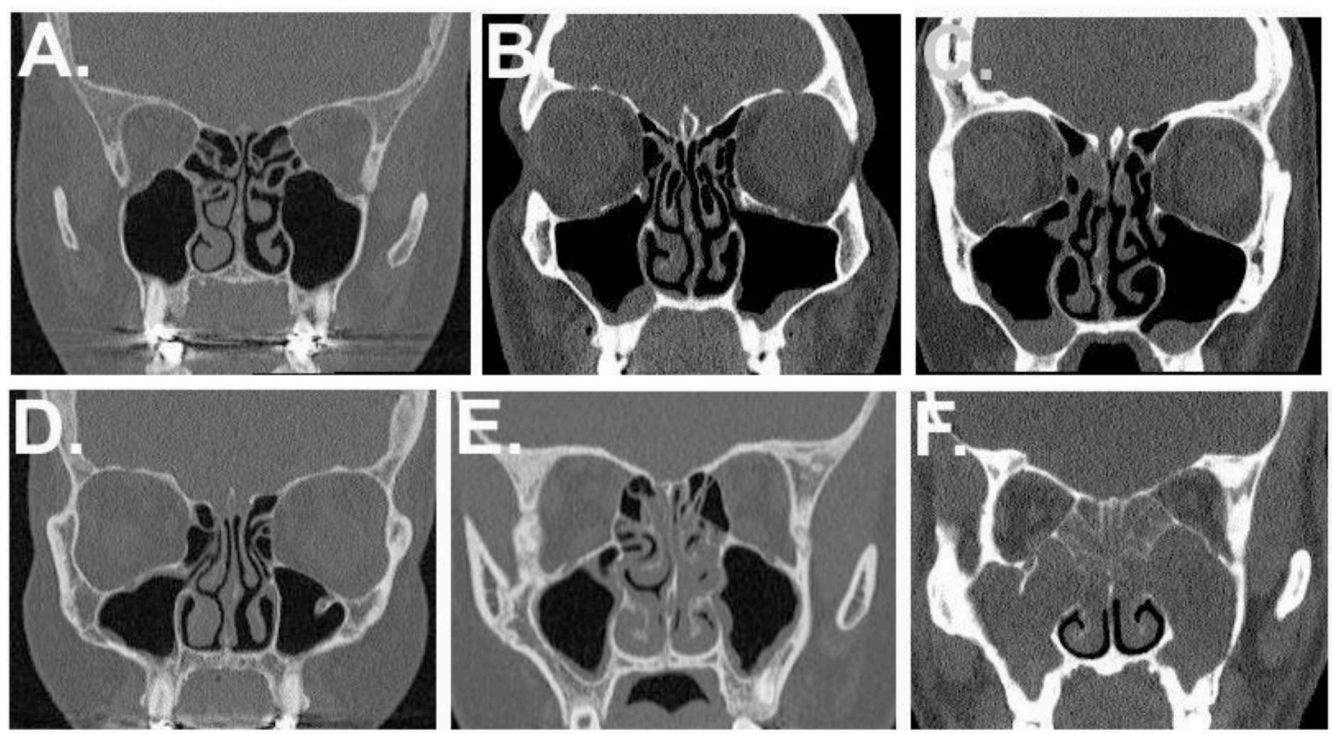

Fig. (1). Evaluation of radiologic signs of nasal polyposis from sinus Computed Tomography (CT) scans. Sinus CT scans that were routinely performed due to clinical purposes. The radiologic NP score was formed based on collected data of the CT scans to evaluation form that was filled by an experienced Radiologist (AM) blinded to patient's history (12). Sinus mucosal findings were scored as $0=$ no change, $1=$ mucosal thickening, $2=$ polypous mucosal thickening \pm discharge. Detectability of turbinate structures was scored as $0=$ detected; $1=$ not detectable. The reasons for "not detectable" responses were poor visualization of middle turbinate due to polypoid change or operative modification of turbinate, both considered to be signs of NP. The radiologic NP score 8-16 was suggestive for clinical CRSwNP phenotype. (A) No CT signs of polypous sinus mucosa. Turbinate anatomy is detectable. Radiologic NP score $=0$. (B) Polypous maxillary sinus mucosa on both sides. No mucosal swelling of anterior ethmoidal cells. Turbinate anatomy is detectable. Radiologic score $=4$. (C) Polypous maxillary sinus mucosa. Mucosal swelling of anterior ethmoidal cells. Turbinate anatomy is detectable. Radiologic score $=6$. (D) No polypous sinus mucosa. Right inferior turbinate fine structure is undetectable. Radiologic score $=1$. (E) Mucosal swelling of right maxillary sinus as well as anterior ethmoidal cells (not shown) and posterior ethmoidal cells. Polypous mucosa of left maxillary sinus. The anatomical fine structure of Inferior and middle turbinates is undetectable. Radiologic score 11. (F) Polypous mucosa of maxillary sinuses and anterior ethmoidal cells (not shown) and posterior ethmoidal cells. The anatomical fine structure of middle turbinates is undetectable. The fine structure of inferior turbinates is detectable. Radiologic score 14.

$p=0.048$, respectively, Table 1). The median age of the CRSwNP group was significantly higher compared to the CRSsNP group ( $p<0.001$, Table 1). The median total LM score of sinus CT scans of the CRSwNP group was significantly higher compared to the CRSsNP group $(p<.001$, Table 1). Higher proportion of CRS patients reported obstruction, postnasal drip and/or facial pain/pressure as one of their worst symptom compared to controls ( $p<0.003$, Table 1).

Total radiologic NP score gave an AUROC of $0.95(95 \%$ CI $0.91-1.00), p<0.001$ (Fig. 2). With the threshold value total radiologic NP score $\geq 8 / 16$, the sensitivity for detecting CRSwNP from CRSwNP group was $94 \%$ while specificity was $82 \%$ (Fig. 2). When using the cut-off value of eight in Radiologic NP score, $6 \%$ of CRSwNP patients did not have radiologic signs of NPs while $18 \%$ of CRSsNP patients had radiologic signs of NPs $(p<0.001$, Table 1). Total LM score gave an AUROC of 0.84 (95\% CI 0.75-0.94), $p<0.001$ (Fig. 2). With the threshold LM score $\geq 9 / 24$ the sensitivity and specificity for detecting CRSwNP from CRSwNP group was $78 \%$ and $69 \%$ respectively.

\section{Table 1. Subject characteristics}

\begin{tabular}{|c|c|c|c|c|c|c|c|c|}
\hline & \multicolumn{2}{|c|}{ Control } & \multicolumn{4}{|l|}{ CRS } & \multirow[b]{2}{*}{$\mathbf{p}^{1}$} & \multirow[b]{2}{*}{$\mathbf{p}^{2}$} \\
\hline & & & CRSs & & CRSw & NNP & & \\
\hline & $\mathrm{N}=\mathbf{6 0}$ & $\%$ & $\mathrm{~N}=55$ & $\%$ & $\mathrm{~N}=18$ & $\%$ & & \\
\hline \multicolumn{9}{|l|}{ Gender } \\
\hline Female & 43 & 72 & 38 & 69 & 6 & 33 & .20 & .012 \\
\hline Male & 17 & 28 & 17 & 31 & 12 & 67 & & \\
\hline Age, median (Q1-Q3) & 33 & $(25-41)$ & 37 & $(30-46)$ & 54 & $(42-62)$ & $<.001$ & $<.001$ \\
\hline \multicolumn{9}{|l|}{$\mathrm{AR}$} \\
\hline no & 16 & 27 & 26 & 47 & 7 & 40 & & \\
\hline yes & 44 & 73 & 29 & 53 & 11 & 61 & .031 & .59 \\
\hline \multicolumn{9}{|l|}{ Asthma } \\
\hline no & 57 & 95 & 49 & 89 & 8 & 44 & & \\
\hline
\end{tabular}


(Table 1) contd.....

\begin{tabular}{|c|c|c|c|c|c|c|c|c|}
\hline & \multicolumn{2}{|c|}{ Control } & \multicolumn{4}{|l|}{ CRS } & \multirow{3}{*}{$\mathbf{p}^{1}$} & \multirow{3}{*}{$\mathbf{p}^{2}$} \\
\hline & & & \multicolumn{2}{|c|}{ CRSsNP } & \multicolumn{2}{|c|}{ CRSwNP } & & \\
\hline & $\mathrm{N}=60$ & $\%$ & $N=55$ & $\%$ & $\mathrm{~N}=18$ & $\%$ & & \\
\hline yes & 3 & 5 & 6 & 11 & 10 & 56 & .006 & $<.001$ \\
\hline \multicolumn{9}{|l|}{ AERD } \\
\hline no & 58 & 97 & 41 & 95 & 13 & 77 & & \\
\hline yes & 2 & 3 & 2 & 5 & 4 & 24 & .27 & .048 \\
\hline \multicolumn{9}{|l|}{ Smoking } \\
\hline never & 51 & 85 & 28 & 51 & 10 & 59 & & \\
\hline ex & 9 & 15 & 9 & 16 & 4 & 24 & & \\
\hline current & 0 & 0 & 18 & 33 & 3 & 18 & $<.001$ & .49 \\
\hline \multicolumn{9}{|l|}{ Previous operation } \\
\hline no & 59 & 98 & 45 & 82 & 13 & 72 & & \\
\hline yes & 1 & 2 & 10 & 18 & 5 & 28 & .001 & .50 \\
\hline \multicolumn{9}{|l|}{ Medication } \\
\hline no intranasal corticosteroid & 37 & 62 & 15 & 27 & 4 & 22 & $<.001$ & .77 \\
\hline intranasal corticosteroids & 23 & 38 & 40 & 73 & 14 & 78 & & \\
\hline \multicolumn{9}{|l|}{ Medication of exacerbation(s) /y } \\
\hline \multicolumn{9}{|l|}{$\geq 1$ peroral corticosteroid course } \\
\hline no & 59 & 100 & 48 & 87 & 15 & 83 & & \\
\hline yes & 0 & 0 & 7 & 13 & 3 & 17 & .002 & .70 \\
\hline \multicolumn{9}{|l|}{$\geq 4$ antibiotic courses } \\
\hline no & 39 & 100 & 40 & 73 & 15 & 83 & & \\
\hline yes & 0 & 0 & 15 & 27 & 3 & 17 & $<.001$ & .53 \\
\hline \multicolumn{9}{|l|}{ Reported worst symptom(s) } \\
\hline \multicolumn{9}{|l|}{ Obstruction, $\mathrm{n}(\%)$} \\
\hline no & 46 & 87 & 30 & 57 & 10 & 56 & & \\
\hline yes & 7 & 13 & 23 & 43 & 8 & 44 & $<.001$ & 1.0 \\
\hline \multicolumn{9}{|l|}{ Postnasal drip, n (\%) } \\
\hline no & 50 & 94 & 37 & 70 & 15 & 83 & & \\
\hline yes & 3 & 6 & 16 & 30 & 3 & 17 & .002 & .36 \\
\hline \multicolumn{9}{|l|}{ Discharge, n (\%) } \\
\hline no & 50 & 94 & 48 & 91 & 16 & 89 & & \\
\hline yes & 3 & 6 & 5 & 9 & 2 & 11 & .51 & 1.0 \\
\hline Pain/pressure, n (\%) & & & & & & & & \\
\hline no & 53 & 100 & 34 & 64 & 15 & 83 & & \\
\hline yes & 0 & 0 & 19 & 36 & 3 & 17 & $<.001$ & .15 \\
\hline Loss of sense of smell, n (\%) & & & & & & & & \\
\hline no & 52 & 98 & 53 & 100 & 16 & 89 & & \\
\hline yes & 1 & 2 & 0 & 0 & 2 & 11 & 1.0 & .062 \\
\hline Dyspnoea, n (\%) & & & & & & & & \\
\hline no & 53 & 100 & 52 & 98 & 16 & 89 & & \\
\hline yes & 0 & 0 & 1 & 2 & 2 & 11 & .26 & .16 \\
\hline Family history of NP & & & & & & & & \\
\hline no & 42 & 75 & 18 & 43 & 9 & 53 & & \\
\hline yes & 7 & 13 & 6 & 14 & 1 & 6 & & \\
\hline don't know & 7 & 13 & 18 & 42 & 7 & 41 & .001 & .72 \\
\hline Family history of AR & & & & & & & & \\
\hline no & 23 & 40 & 28 & 65 & 8 & 47 & & \\
\hline yes & 29 & 50 & 12 & 28 & 5 & 29 & & \\
\hline don't know & 6 & 10 & 3 & 7 & 4 & 24 & .05 & .20 \\
\hline Family history of asthma & & & & & & & & \\
\hline no & 32 & 56 & 24 & 57 & 7 & 41 & & \\
\hline yes & 21 & 37 & 16 & 38 & 6 & 35 & 1.0 & .11 \\
\hline don't know & 5 & 9 & 2 & 5 & 4 & 24 & & \\
\hline
\end{tabular}


(Table 1) contd.....

\begin{tabular}{|c|c|c|c|c|c|c|c|c|}
\hline & \multicolumn{2}{|c|}{ Control } & \multicolumn{4}{|l|}{ CRS } & \multirow{3}{*}{$\mathbf{p}^{1}$} & \multirow{3}{*}{$\mathbf{p}^{2}$} \\
\hline & \multirow[b]{2}{*}{$\mathrm{N}=60$} & \multirow[b]{2}{*}{$\%$} & \multicolumn{2}{|c|}{ CRSsNP } & \multicolumn{2}{|c|}{ CRSwNP } & & \\
\hline & & & $\mathbf{N}=\mathbf{5 5}$ & $\%$ & $\mathrm{~N}=18$ & $\%$ & & \\
\hline \multicolumn{9}{|l|}{ Other diseases } \\
\hline no & 48 & 84 & 31 & 57 & 9 & 53 & & \\
\hline yes & 9 & 16 & 23 & 43 & 8 & 47 & .001 & .79 \\
\hline \multicolumn{9}{|l|}{ Self-reported NP } \\
\hline no & 58 & 97 & 45 & 82 & 6 & 33 & & \\
\hline yes & 0 & 0 & 10 & 18 & 12 & 67 & .002 & $<.001$ \\
\hline don't know & 2 & 3 & 0 & 0 & 0 & 0 & & \\
\hline \multicolumn{9}{|l|}{ Endoscopic signs of $\mathrm{NP}^{3}$} \\
\hline no & 60 & 100 & 55 & 100 & 0 & 0 & & \\
\hline yes & 0 & 0 & 0 & 0 & 18 & 100 & $<.001$ & $<.001$ \\
\hline \multicolumn{9}{|l|}{ Radiologic NP score ${ }^{4}$} \\
\hline $0-7$ & - & - & 45 & 82 & 1 & 6 & - & $<.001$ \\
\hline $8-16$ & - & - & 10 & 18 & 17 & 94 & & \\
\hline Total LM score of CT scans, median (Q1-Q3) & - & - & 4.0 & $(2-10)$ & 12 & $(9-14.25)$ & - & $<.001$ \\
\hline
\end{tabular}

$\mathrm{p}^{1}=\mathrm{CRS}$ patients $v s$. controls. $\mathrm{p}^{2}=\mathrm{CRSsNP} v$ s. CRSwNP. CRS $=$ chronic rhinosinusitis; $\mathrm{AR}=$ allergic rhinitis; $\mathrm{AERD}=\mathrm{aspirin}$ exacerbated respiratory disease; $\mathrm{NP}=$ nasal polyps; $\mathrm{CT}$ scan signs of $\mathrm{NP}$ was based on the presence of mucosal NP-suggestive changes of inferior and/or middle turbinate(s), with score $0=$ no, $1=$ yes. Total score $0=$ No NP, total score $1-4=$ NP; LM=LundMackay score of sinus Computed Tomography (CT) scans.Q1, Q3: $25 \%$ and $75 \%$ percentiles respectively. ${ }^{3}$ Deviation from protocol: NP diagnosed by anterior rhinoscopy from $n=20$ controls by an Otorhinolaryngologist. ${ }^{4}$ Sum of maxillary/ethmoid sinus mucosal findings (scored as $0=$ no change, $1=$ mucosal thickening, $2=$ polypous mucosal thickening \pm discharge) and detectability of turbinate structures (scored as $0=$ detected; $1=$ not detectable). $P$ values by Fisher's exact test (dichotomous variables) or Mann Whitney U test (continuous variables).

Table 2. Criteria of radiologic Nasal Polyp (NP) score.

\begin{tabular}{|l|l|l|}
\hline & Right \\
\hline Sinus mucosal findings & $0-2$ & Left \\
Maxillary sinus & $0-2$ \\
Anterior ethmoidal cells & $0-2$ \\
Posterior ethmoidal cells & $0-2$ \\
\hline $\begin{array}{l}\text { Detectability of turbinate structures }{ }^{1} \\
\text { Inferior turbinate }\end{array}$ & $0-2$ \\
Middle turbinate & $0-1$ \\
\hline Total & $0-1$ \\
\hline $\begin{array}{l}\text { Sinus Computed Tomography (CT) scans that were routinely performed due to clinical purposes to a random sample of patients undergoing CRS-surgical consultation. The } \\
\text { radiologic NP score was formed based on previously described data of evaluation form that was filled by an experienced Radiologist (AM) blinded to patient's history. } \\
\text { Sinus mucosal findings were scored as 0=no change, 1=mucosal thickening, 2= polypous mucosal thickening } \pm \text { discharge. Detectability of turbinate structures was scored as } \\
0=\text { detected; } 1=\text { not detectable. The reasons for "not detectable" responses were poor visualization of middle turbinate due to polypoid change or operative modification of } \\
\text { turbinate, both considered to be signs of NP. 'Concha bullosa, paradoxical turbinate, turbinate hypertrophy. }\end{array}$ & $0-1$ \\
\end{tabular}

A total of $33 \%$ of CRSwNP patients reported not having NPs and $18 \%$ of CRSsNP patients reported having NPs ( $<<.001$, Table 1). While $27 \%$ of patients with radiologic signs of NPs reported not having NPs, $22 \%$ of patients with radiologic signs of NPs reported having NPs $(p<0.001$, Table 1).

Binary logistic regression was conducted to evaluate the positive and negative family history of NPs and its association with the control and CRS groups. When evaluating the family history, $14 \%$ of controls and $21 \%$ of CRS group had positive family history of NP $(p=.45$, Table 3$)$. The corresponding percentages of positive family history of asthma were also not significantly different between controls (40\%) and CRS (42\%) $(p=0.084)$. Interestingly, we found a significant association with positive family history of AR, $56 \%$ in controls to $32 \%$ in the group CRS ( $p=0.015$, Table 3 ).

Finally, we wanted to evaluate the proportion of subjects not knowing their family history of NP, asthma or AR. Control group and CRS group knew similarly their family history of asthma ( $p=0.077$, Table 4), and AR ( $p=0.082$, Table 4). In contrast, the knowledge of family history of NPs in the CRS group was significantly poorer compared to the control group (adjusted OR=6.02, 95\% CI 1.98-18.30, $p=0.002$, Table 4).

\section{DISCUSSION}

This study was carried out to study the relationship between endoscopic-, radiologic-, self-reported CRSwNP, and family history in detecting CRSwNP. We hypothesised that radiologic, self-reported and heredity of NPs could be able to 


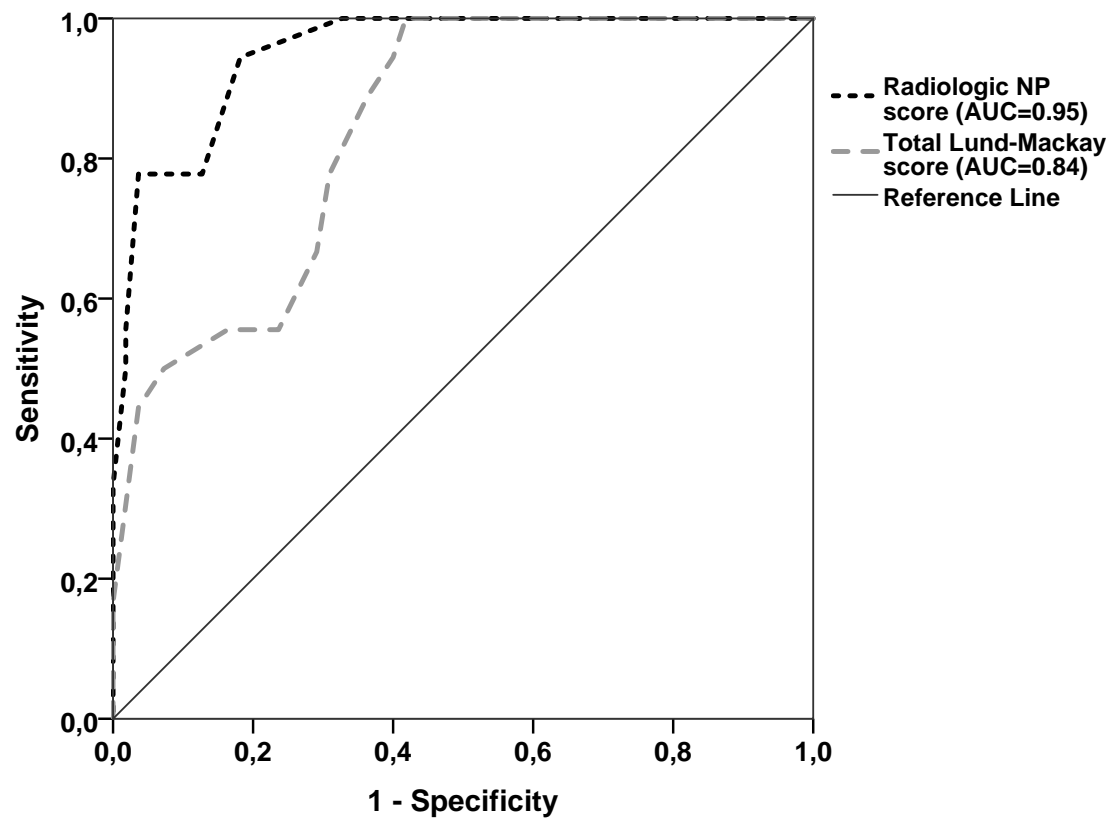

Fig. (2). The Receiver operating characteristic (ROC) discrimination curve of prediction models for CRSsNP group ( $\mathrm{n}=55$ ) over CRSwNP group $(\mathrm{n}=18)$. Total radiologic NP score gave an AUROC of $0.95(95 \%$ CI $0.91-1.00), p<0.001$. With the threshold value total radiologic NP score $\geq 8 / 16$, the sensitivity was $94 \%$ and specificity $82 \%$ for detecting CRSwNP from CRSsNP group. Total LM score gave an AUROC of 0.84 (95\% CI $0.75-0.94), p<0.001$. With the threshold value LM score $\geq 9 / 24$ the sensitivity was $78 \%$ and specificity $69 \%$ for detecting CRSwNP from CRSsNP group.

Table 3. Association of family history of NP, asthma and AR with chronic rhinosinusitis.

\begin{tabular}{|c|c|c|c|c|c|c|c|c|}
\hline & \multicolumn{2}{|c|}{ Controls } & \multicolumn{2}{|c|}{ CRS } & \multirow[b]{2}{*}{ OR } & \multicolumn{2}{|l|}{ CI } & \multirow[b]{2}{*}{$\mathbf{P}$} \\
\hline & $\mathbf{N}$ & $\%$ & $\mathbf{N}$ & $\%$ & & lower & upper & \\
\hline \multicolumn{9}{|c|}{ Family history of NP } \\
\hline No & 42 & 86 & 27 & 79 & 1.0 & & & \\
\hline Yes & 7 & 14 & 7 & 21 & 1.56 & 0.49 & 4.93 & .45 \\
\hline \multicolumn{9}{|c|}{ Family history of asthma } \\
\hline No & 32 & 60 & 31 & 59 & 1.0 & & & \\
\hline Yes & 21 & 40 & 22 & 42 & 1.08 & .50 & 2.34 & .84 \\
\hline \multicolumn{9}{|c|}{ Family history of AR } \\
\hline No & 23 & 44 & 36 & 68 & 1.0 & & & \\
\hline Yes & 29 & 56 & 17 & 32 & .38 & .17 & .83 & .015 \\
\hline
\end{tabular}

CRS= Chronic Rhinosinusitis; $\mathrm{CI}=$ Confidence Interval; OR= Odds Ratio

Table 4. Association of knowledge of the family history of NP, asthma and AR with chronic rhinosinusitis.

\begin{tabular}{|c|c|c|c|c|c|c|c|c|c|c|c|c|}
\hline & \multicolumn{2}{|c|}{ Controls } & \multicolumn{2}{|c|}{ CRS } & \multirow[b]{2}{*}{$\mathrm{OR}_{1}$} & \multicolumn{2}{|l|}{ CI } & \multirow[b]{2}{*}{$\mathbf{P}^{1}$} & \multirow[b]{2}{*}{$\mathrm{OR}_{2}$} & \multicolumn{2}{|l|}{ CI } & \multirow[b]{2}{*}{$\mathbf{P}^{2}$} \\
\hline & $\mathbf{N}$ & $\%$ & $\mathbf{N}$ & $\%$ & & lower & upper & & & lower & upper & \\
\hline \multicolumn{13}{|c|}{ Family history of NP } \\
\hline Know & 49 & 88 & 34 & 58 & 1.0 & & & & 1.0 & & & \\
\hline Don't know & 7 & 13 & 25 & 42 & 5.15 & 2.0 & 13.2 & .001 & 6.02 & 1.98 & 18.30 & .002 \\
\hline \multicolumn{13}{|c|}{ Family history of asthma } \\
\hline Know & 53 & 91 & 53 & 88 & 1.0 & & & & & & & \\
\hline Don't know & 5 & 9 & 6 & 12 & 1.2 & .35 & 4.17 & .77 & & & & \\
\hline \multicolumn{13}{|c|}{ Family history of AR } \\
\hline Know & 52 & 90 & 53 & 88 & 1.0 & & & & & & & \\
\hline Don't know & 6 & 10 & 7 & 12 & 1.15 & .36 & 3.64 & .82 & & & & \\
\hline
\end{tabular}

$\mathrm{CRS}=$ Chronic Rhinosinusitis; $\mathrm{CI}=$ Confidence Interval; $\mathrm{OR}=$ Odds Ratio; $\mathrm{OR}_{1}=$ crude, $\mathrm{OR}_{2}=$ adjusted by age, gender, presence of $\mathrm{AR}$ and presence of asthma. $\mathrm{NP}=\mathrm{Nasal}$ Polyps; AR= Allergic Rhinitis. 
predict CRSwNP phenotype. Studies support that early awareness and early treatment of CRSwNP might prevent progressive and severe disease forms as well as development of asthma $[10,11]$. Thus studying predictive potential of radiologic and reported NP signs could be useful in situations where nasal endoscopy is not available, such as in primary care or during visits at another specialist other than an Otorhinolaryngologist.

We were able to develop a radiologic NP score with good specificity and sensitivity to detect CRSwNP from CRSsNP. The score was based on findings in nasal turbinates and maxillary, anterior/posterior ethmoid cells showing that polypoid sinus mucosa and/or non-detectable middle/inferior turbinate(s) were most indicative for CRSwNP phenotype. Total LM showed a moderate specificity and sensitivity to detect CRSwNP from CRSsNP. Larger well-characterized prospective cohort studies are needed to further evaluate predictive algorithms based on CT scan findings.

In addition to radiologic NP score, self-reported NPs associated with CRSwNP phenotype. This might indicate that in situations of lacking the possibility to perform nasal endoscopy, early recognition of CRSwNP might benefit form information obtained from both sinus CT scans and patients, in addition to clinical examination and proper patient interview. In this study, patients were asked the presence of NPs when referred to a CRS-surgical consultation at the University Hospital, which might have increased self-awareness of NPs. Hence true positive and false negative rates of self-reported NPs might be lower in general population which might lead to poorer predictability of self-reported NPs for CRSwNP phenotype. A study of school students showed that of 131 diagnosed asthma cases, 118 (90\%) were aware about their diagnosis indicating the need for health education of airway diseases [15].

Strikingly, contrary to expectation, family history of NPs did not associate with CRSwNP or CRS. This could be associated with the observation that CRS patients were uncertain concerning family history when reporting NPs compared to controls. Additional evidence for this line of thinking comes from other studies showing poor accuracy in reporting family history of diseases such as colorectal cancer or prostate cancer [16 - 18]. It could thus be speculated that, younger age of controls, as in our study, could in part explain them to be more astute when seeking information and hence be more aware of family history and health related issues. On the other hand, our models were adjusted by age, gender, presence of AR and asthma.

Family history of allergy and/or asthma was given with higher certainty both in CRS and control groups compared to family history of NP, which was given with uncertainty. Poor knowledge of NPs heredity could indicate an unmet need to improve patient education in order to detect patients at risk to develop recalcitrant CRSwNP early and to improve their respiratory health. Our study also highlights an important need to improve questionnaires to better detect positive family history of CRSwNP. The question "Do you have a family history of NP" will putatively need additional questions such as "Has a family member complained symptoms of CRS such as loss of nasal obstruction, discharge, facial pain or loss of sense of smell?" or "Has a family member undergone a paranasal sinus operation and/or polypectomy?". Future studies are therefore needed to validate whether additional questions would improve possibilities to gather knowledge of inherited CRSwNP.

This study has several limitations. The sample size was small and not population based. CRS population presented a random sample of CRS patients visiting CRS-surgical consultation and thus the limited number of CRSwNP patients. There might have been limitations in the variables collected from patient records. We acknowledge that lack of SNOT22, endoscopic NP score, NP eosinophilia, and socioeconomic status limits the interpretation of the findings.

\section{CONCLUSION}

The study demonstrated that radiologic NP score and selfreported NPs associated with endoscopic NPs. This might be clinically useful in situations where nasal endoscopy is unavailable, in order to hit early progressive CRSwNP. Family history of CRSwNP had less predictive value. Validation studies with larger population are still needed.

\section{DISCLOSURE}

This study was funded in part by the grants of the Finnish cultural foundation, the Hospital Districts of Tampere and of Helsinki and Uusimaathe Tampere Tuberculosis association, the Finnish Association of Otorhinolaryngology and Head and Neck Surgery, Finnish Medical Foundation, the Finnish Society of Allergology and Clinical Immunology, Jane and Aatos Erkko Foundation, Paulo Foundation, Yrjö Jahnsson Foundation and Väinö and Laina Kivi Foundation. The authors report no conflicts of interest.

\section{LIST OF ABBREVIATIONS}

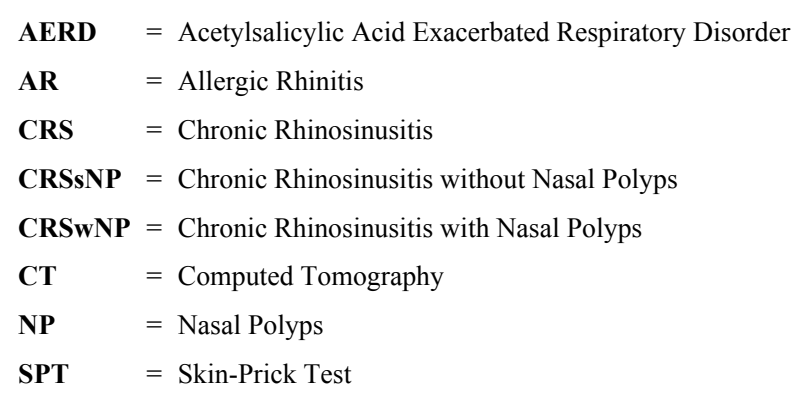

\section{ETHICS APPROVAL AND CONSENT TO PARTI- CIPATE}

The study was approved by the ethical committees of the Pirkanmaa Hospital district (no R06187, R04044) and of Hospital District of Helsinki and Uusimaa (no 19/13/03/00/11).

\section{HUMAN AND ANIMAL RIGHTS}

No Animals were used in this research. All human research procedures followed were in accordance with the ethical standards of the committee responsible for human experimentation (institutional and national), and with the Helsinki Declaration of 1975, as revised in 2013. 


\section{CONSENT FOR PUBLICATION}

Written informed consent was obtained from each patient.

\section{AVAILABILITY OF DATA AND MATERIALS}

The restrictions is applied on the data that support the findings of this study because the Finnish Legistration does not allow data sharing.

\section{FUNDING}

This study was funded in part by the grants of the Finnish cultural foundation, the Hospital Districts of Tampere and of Helsinki and Uusimaathe Tampere Tuberculosis association, the Finnish Association of Otorhinolaryngology and Head and Neck Surgery, Finnish Medical Foundation, the Finnish Society of Allergology and Clinical Immunology, Jane and Aatos Erkko Foundation, Paulo Foundation, Yrjö Jahnsson Foundation and Väinö and Laina Kivi Foundation.

\section{CONFLICT OF INTEREST}

The author declares no conflict of interest, financial or otherwise.

\section{ACKNOWLEDGEMENTS}

We wish to thank Marja-Leena Oksanen for excellent assistance, Matti Karjalainen, Prasun Dastidar and all the volunteers.

\section{REFERENCES}

[1] Fokkens WJ, Lund VJ, Mullol J, Bachert C, Alobid I, Baroody F, et al. European position paper on rhinosinusitis and nasal polyps 2012 . Rhinol Suppl 2012; 23(3 p preceding table of contents): 1-298.

[2] Hastan D, Fokkens WJ, Bachert C, et al. Chronic rhinosinusitis in Europe--an underestimated disease. A GA2 LEN study. Allergy 2011; 66(9): 1216-23.

[http://dx.doi.org/10.1111/j.1398-9995.2011.02646.x] [PMID: 2160 5125]

[3] Greisner WA III, Settipane GA. Hereditary factor for nasal polyps. Allergy Asthma Proc 1996; 17(5): 283-6. [http://dx.doi.org/10.2500/108854196778662192] [PMID: 8922148]

[4] Delagrand A, Gilbert-Dussardier B, Burg S, et al. Nasal polyposis: Is there an inheritance pattern? A single family study. Rhinology 2008; 46(2): $125-30$

[PMID: 18575014]
[5] Alexiou A, Sourtzi P, Dimakopoulou K, Manolis E, Velonakis E. Nasal polyps: Heredity, allergies, and environmental and occupational exposure. J Otolaryngol Head Neck Surg 2011; 40(1): 58-63. [PMID: 21303603]

[6] Bohman A, Oscarsson M, Holmberg K, et al. Heredity of nasal polyps Rhinology 2015; 53(1): 25-8.

[http://dx.doi.org/10.4193/Rhin14.032] [PMID: 25756074]

[7] Brozek JL, Bousquet J, Baena-Cagnani CE, et al. Allergic Rhinitis and its Impact on Asthma (ARIA) guidelines: 2010 revision. J Allergy Clin Immunol 2010; 126(3): 466-76.

[http://dx.doi.org/10.1016/j.jaci.2010.06.047] [PMID: 20816182]

[8] Becker AB, Abrams EM. Asthma guidelines: The Global Initiative for Asthma in relation to national guidelines. Curr Opin Allergy Clin Immunol 2017; 17(2): 99-103.

[http://dx.doi.org/10.1097/ACI.0000000000000346] [PMID: 2811 8238]

[9] Ahmadiafshar A, Farjd HR, Moezzi F, Mousavinasab N. Nasal polyposis in patients with asthma and allergic rhinitis. J Laryngol Otol 2012; 126(8): 780-3.

[http://dx.doi.org/10.1017/S0022215112000771] [PMID: 22691577]

[10] Hellings PW, Fokkens WJ, Akdis C, et al. Uncontrolled allergic rhinitis and chronic rhinosinusitis: Where do we stand today? Allergy 2013; 68(1): 1-7.

[http://dx.doi.org/10.1111/all.12040] [PMID: 23025484]

[11] Hopkins C, Andrews P, Holy CE. Does time to endoscopic sinus surgery impact outcomes in chronic rhinosinusitis? Retrospective analysis using the UK clinical practice research data. Rhinology 2015; 53(1): 18-24.

[http://dx.doi.org/10.4193/Rhin14.077] [PMID: 25756073]

[12] Julkunen A, Terna E, Numminen J, et al. Inter-observer agreement of paranasal sinus computed tomography scans. Acta Otolaryngol 2017; 137(6): 611-7.

[http://dx.doi.org/10.1080/00016489.2016.1262552] [PMID: 2798 1879]

[13] Lund VJ, Kennedy DW. Staging for rhinosinusitis. Otolaryngol Head Neck Surg 1997; 117(3 Pt 2): S35-40.

[http://dx.doi.org/10.1016/S0194-5998(97)70005-6] [PMID: 9334786]

[14] Luukkainen A, Karjalainen J, Honkanen T, Lehtonen M, Paavonen T, Toppila-Salmi S. Indoleamine 2,3-dioxygenase expression in patients with allergic rhinitis: A case-control study. Clin Transl Allergy 2011; 1(1): 17-7022-1-17.

[15] Stern S, Gavish A, Zin D, Tzivoni D. Clinical outcome of silent myocardial ischemia. Am J Cardiol 1988; 61(12): 16F-8F. [http://dx.doi.org/10.1016/0002-9149(88)90049-5] [PMID: 3282418]

[16] Gaff CL, Aragona C, MacInnis RJ, et al. Accuracy and completeness in reporting family history of prostate cancer by unaffected men. Urology 2004; 63(6): 1111-6.

[http://dx.doi.org/10.1016/j.urology.2003.12.032] [PMID: 15183962]

[17] Mitchell RJ, Brewster D, Campbell H, et al. Accuracy of reporting of family history of colorectal cancer. Gut 2004; 53(2): 291-5. [http://dx.doi.org/10.1136/gut.2003.027896] [PMID: 14724166]

[18] Bias in the reporting of family history: implications for clinical care. J Genet Couns 2012; 21(4): 547-56.

(C) 2019 Luukkainen et al.

This is an open access article distributed under the terms of the Creative Commons Attribution 4.0 International Public License (CC-BY 4.0), a copy of which is available at: https://creativecommons.org/licenses/by/4.0/legalcode. This license permits unrestricted use, distribution, and reproduction in any medium, provided the original author and source are credited. 